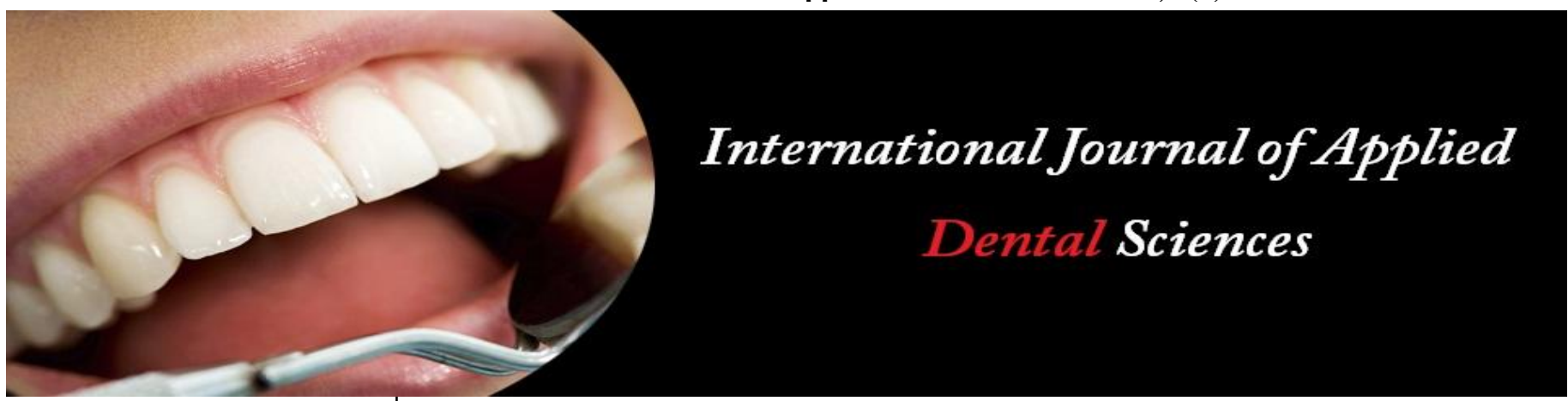

ISSN Print: 2394-7489

ISSN Online: 2394-7497

IJADS 2017; 3(4): 16-20

(C) 2017 IJADS

www.oraljournal.com

Received: 03-08-2017

Accepted: 04-09-2017

Dr. Githanjali Manchikalapudi

Reader, Department of

Prosthodontics, Army College of Dental Sciences, Secunderabad,

Telangana, India

Dr. Aditi Prasad

Previously Post Graduate

Student, Department of

Prosthodontics, Army College of

Dental Sciences, Secunderabad,

Telangana, India

Dr. Laxman Rao Polasani Professor \& HOD, Department of Prosthodontics, Army College of Dental Sciences,

Secunderabad, Telangana, India

Correspondence

Dr. Githanjali Manchikalapudi

Reader, Department of

Prosthodontics, Army College of

Dental Sciences, Secunderabad,

Telangana, India

\section{Attitude of partial denture wearers towards implant treatment and its association with oral hygiene status, age, gender and extent of edentulousness - $A$ cross sectional study}

\author{
Dr. Githanjali Manchikalapudi, Dr. Aditi Prasad and Dr. Laxman Rao \\ Polasani
}

\section{Abstract}

Back ground: Removable partial dentures are an inexpensive mode of treatment to effectively replace teeth, but higher incidence of plaque, mobility of the teeth and caries is associated with them. Dental implants, that are long considered a standard of care in fixed prostheses, can improve the overall quality of restoration in partial denture wearers.

Materials and methods: 50 partial denture wearers were studied to assess their attitude towards implant treatment. Correlation between oral hygiene status, age, gender and extent of edentulousness were also evaluated.

Results: 19 out of the 40 patients were not willing for implant treatment. Significant difference $(p=0.045)$ was seen between oral hygiene status of patients willing for implant treatment and those not willing.

Conclusion: About 50\% of partial denture wearers were unwilling to accept implant treatment. Within the limitations of the study it can be concluded that patient perceived higher cost of implants and less awareness about oral hygiene can be associated with unwillingness of removable partial denture wearers to opt for a implant treatment.

Keywords: Attitude, dental implant, dental prostheses, high cost, oral hygiene index, patient education, removable partial denture

\section{Introduction}

Removable partial dentures, for decades, have presented an inexpensive mode of treatment to effectively replace teeth for function and aesthetics. Advent of tooth supported fixed partial dentures and subsequent popularity of implant supported restorations, has not reduced the use of removable partial dentures. However, these dentures promote plaque formation and are a major cause of periodontal problems ${ }^{[1]}$. Increased tooth mobility and caries activity are disturbing outcomes of removable partial denture treatment ${ }^{[2,3]}$. The classification or extent of edentulousness, denture design, fabrication and support also effect periodontal status [4]. Removable dentures also contribute to increasing amount of stress on the remaining natural teeth, mainly the abutment teeth ${ }^{[5]}$. In addition, the necessity to remove the denture every day makes it an unattractive choice. Many surveys have shown that a great number of distal extension partial dentures made are never worn. Nevertheless, failure to replace teeth can lead to ill effects, mainly in young adults ${ }^{[1]}$.

Patient education on the importance of oral hygiene and maintenance, coupled with periodic check-up and oral prophylaxis can decrease the risk of periodontal disease in partial denture wearers. Many studies have, time and again, stressed the need for regular check-up and maintenance ${ }^{[6,7-11]}$.

On the other hand, restorations on osseointegrated implants have replaced missing teeth and are stable over a long period of time. In a 15 year longitudinal study, Adell et al 1981 [12] evaluated 2768 osseointegrated dental implants placed and restored in 371 patients. It was found that in $89 \%$ of maxillary and $100 \%$ of mandibular implants, the bridges were continuously stable. 
Implants have fulfilled and exceeded the demands set by the 1978 Harvard Conference on successful dental implantation procedures ${ }^{[13]}$.

Numerous studies also assessed the awareness of general population about the pros and cons of implant treatment, financial implications of the procedure, patient expectations and preference of fixed implant treatment over removable prostheses ${ }^{[14-18]}$. All these studies categorically stated that income levels of the patient is a determining factor in choosing implant treatment, that majority of information gathered by patients is through media and high cost of implants is a major factor that precluded patient preference for the treatment modality.

Removable partial dentures, as a treatment option for partially edentulous patients cannot be ignored. Also attempt should be made by health care providers to extend the long term benefits of implant restorations to partially edentulous removable denture wearers.

With this back ground, a cross sectional study was conducted to study the attitude of partial denture wearers towards implant treatment and its association with oral hygiene status, age, gender and extent of edentulousness.

\section{Materials and methods}

50 partially edentulous patients, irrespective of gender and age were enrolled from the outpatient department of the Department of Prosthodontics, Army college of Dental Sciences, Secunderabad to participate in a cross sectional study, to assess attitude of partially edentulous patients towards implant treatment.

During initial assessment, each participant was subjected to an operator administered questionnaire and clinical examination. [Figure 1] During this interaction, patient satisfaction with present removable partial denture prostheses was recorded and willingness for a fixed alternative treatment was probed. Gross oral hygiene assessment was done and the importance of oral hygiene methods explained using educational tools. The participants were also educated about implant treatment and associated costs. They were motivated to maintain oral hygiene as a prerequisite for further assessment and consideration for implant treatment planning. Patients willing to continue assessment were recalled after 6 weeks. [Figure 2] Out of the 50 participants enrolled, only 40 reported for the recall visit. The objective of recall visit was to assess patient's oral hygiene maintenance and record his or her willingness for implant treatment to replace missing teeth. Oral Hygiene Index, OHI - S (Greene and Vermillion, 1964), was used to assess the participant's oral hygiene status and maintenance after motivation during the initial visit. Debri Index and Calculus Index are part of the OHI- S. Six surfaces, one each in the four posterior segments and two anterior segments were examined. Upper buccal and lower lingual surfaces were examined. The tooth examined in each segment was usually the first molar

\section{Criteria for Debris Index}

1. No debris or stain present

2. Soft debris covering not more than $1 / 3^{\text {rd }}$ of tooth surface, or presence of extrinsic stains without other debris

3. Soft debris covering more than $1 / 3^{\text {rd }}$, but not more than $2 / 3^{\text {rd }}$ of the tooth

4. Soft debris covering more than $2 / 3^{\text {rd }}$ of the tooth exposed.

\section{Criteria Calculus Index}

1. No calculus present

2. Presence of supra gingival calculus not more than $1 / 3^{\text {rd }}$ of exposed tooth surface.

3. Presence of supra gingival calculus more than $1 / 3^{\text {rd }}$ of tooth and not more than $2 / 3^{\text {rd }}$ or presence of individual flecks of sub gingival calculus or both.

4. Presence of more than $2 / 3^{\text {rd }}$ of supra gingival calculus or a continuous heavy band of sub gingival calculus or both.

Final score of OHI Index $=$ Debris score + Calculus score Calculus or Debris score $=($ buccal scores $)+($ lingual scores $) /$ (no. of surfaces scored).

After clinical examination, only patients willing for implant treatment and with good and fair oral hygiene $(0-2.5$ score of $\mathrm{OHI}-\mathrm{S}$ ), without systemic conditions that compromise implant success and with favourable intraoral factors were assessed for implant treatment. Accordingly, implant treatment planning was done in 7 patients out of the 40 studied. Diagnostic casts, radiographs and bone mapping were used and patients were informed regarding the feasibility of implant placement, restoration and associated costs. In patients not willing for implant placement, the reason was recorded.

The data so obtained was subjected to statistical analysis to evaluate the number of participants willing for implant treatment, reasons for not choosing the treatment and association of oral hygiene status, gender, age and extent of edentulousness to patient attitude. The parametric data ie oral hygiene index values and age was analysed using the $\mathrm{T}$ test and the non-parametric data was analysed using Fisher's exact test.

\section{Results}

Out of the 40 participants who reported for the recall visit, poor oral hygiene maintenance was found in $13 \% .48 \%$ of the patients were not willing for the implant treatment. Most of the participants choose not to opt for the implant treatment due to high cost of the treatment. One of the patients was not ready for implant treatment because of the surgical procedure involved and one more preferred removable denture to implant treatment as he perceived implant treatment to be more complicated. $10 \%$ of the patients showed unfavourable systemic condition, mainly uncontrolled diabetes. $13 \%$ of the patients had either decreased inter arch space or insufficient bone or reduced mouth opening that precludes implant treatment. Out of the remaining, $18 \%$ left, only $13 \%$ ie. 5 out of 7 participants reverted back for implant placement. [Figure 3].

The OHI -S index values which represent the oral hygiene status of the participants show a significant difference between the patients willing for implant treatment and those not willing. $(\mathrm{p}=0.045)$

There is no significant difference in the patient willing for implant treatment and those not willing in terms of age, gender or extent of edentulousness ie. being partially edentulous in the maxilla or mandible or both. $(\mathrm{p}=0.149$, $\mathrm{p}=0.348$ and $\mathrm{p}=0.561$ respectively. 


\section{Tables and Figures}

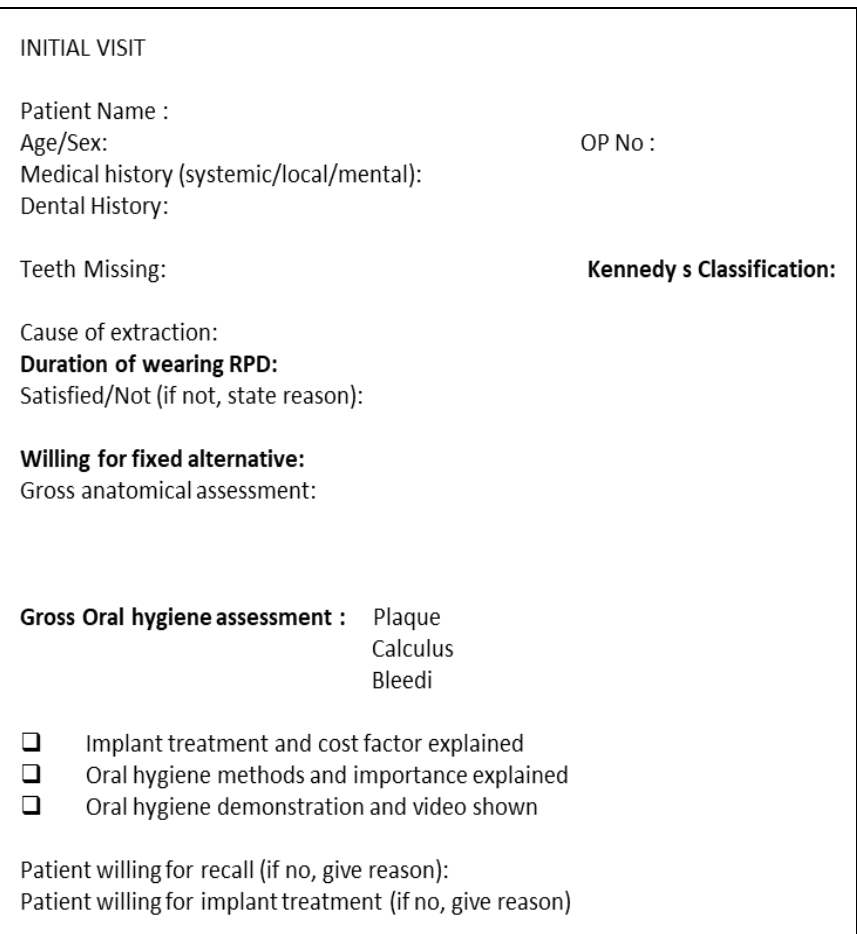

Fig 1: Questionnaire and Check list for initial visit.

RECALL
Patient Name :
Age/Sex:
Oral Hygiene assessment: OHI-S score:
$\quad$ Impressions made and casts poured
$\quad$ OPG taken
$\quad$ IOPA with steel spheres of
$\quad$ Bone mapping done
Edentulous ridge analysis from casts and bone mapping: Dimensions:
Patient willing for implant treatment (If no, give reason):
If ridge split required, possible/not possible:
Radiographic analysis from OPG and IOPA: dimensions available:
Proximity to sinus floor:
Proximity to inferior alveolar nerve canal:
If sinus lift/nerve repositioning required, possible/not possible:

Fig 2: Checklist for recall visit.

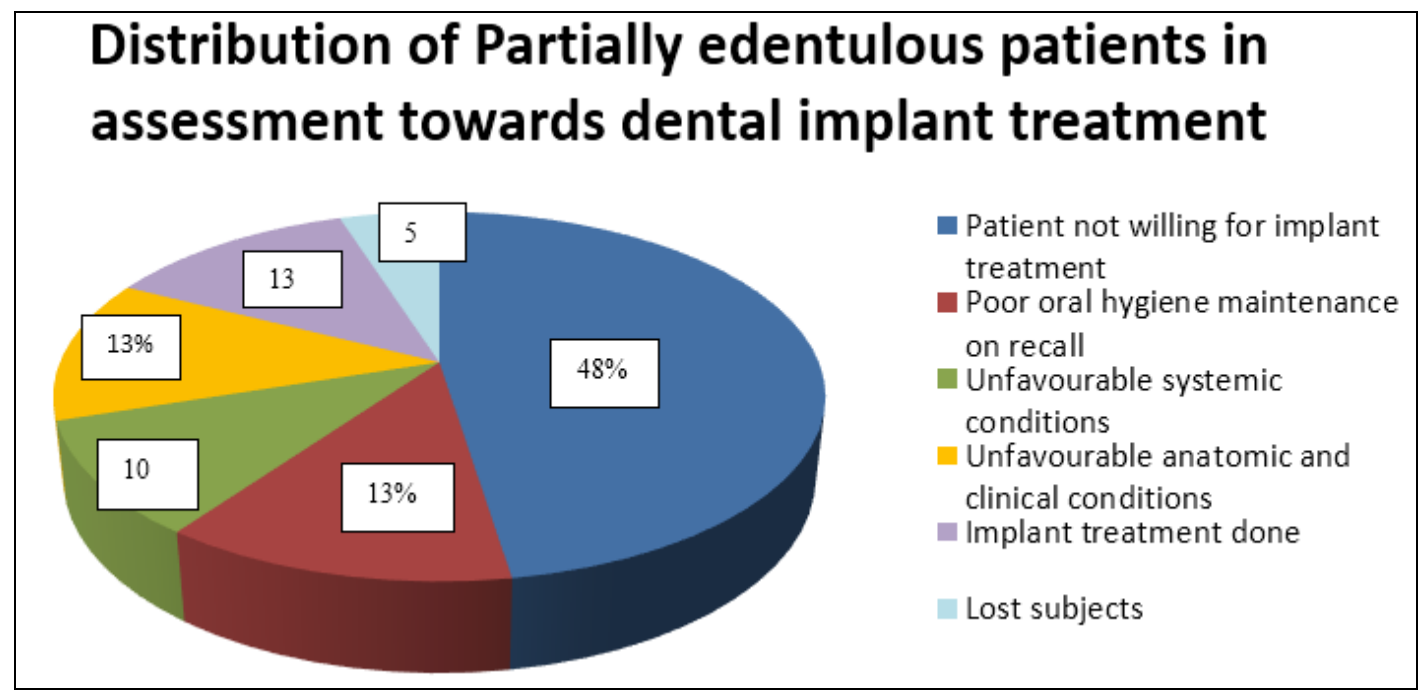

Fig 3: Pie diagram showing percentage distribution of participants in implant treatment planning.

Table 1: Descriptive statistics and $T$ test for oral hygiene status and patient attitude.

\begin{tabular}{|c|c|c|c|c|c|c|c|c|c|}
\hline & $\mathbf{N}$ & Mean & SE Mean & SD & Minimum & Median & Maximum & Difference & \multirow{2}{*}{ T-Value 2.11 P value $0.045^{*}$} \\
\cline { 1 - 7 } NW & 19 & 2.305 & 0.101 & 0.440 & 2.000 & 2.000 & 3.000 & \multirow{2}{*}{$0.54895 \% \mathrm{CI}(0.014,1.082)$} & \\
\hline W & 21 & 1.757 & 0.239 & 1.097 & 0.000 & 2.000 & 3.000 & & \\
\hline
\end{tabular}

*Significant $p<0.05$

$\mathrm{NW}=$ Patients not willing for Implant treatment

$\mathrm{W}=$ Patients willing for Implant treatment

Table 2: Descriptive statistics and $\mathrm{T}$ test for age and patient attitude.

\begin{tabular}{|c|c|c|c|c|c|c|c|c|c|}
\hline & N & Mean & SE Mean & SD & Minimum & Median & Maximum & Difference & \multirow{2}{*}{ T Value 1.48 P value 0.149} \\
\cline { 1 - 7 } NW & 19 & 54.37 & 2.79 & 12.15 & 42.00 & 49.00 & 87.00 & \multirow{2}{*}{$5.8995 \%$ CI $-2.20,13.98$} & \\
\hline W & 21 & 48.48 & 2.86 & 13.10 & 21.00 & 52.00 & 69.00 & & \\
\hline
\end{tabular}

Significant $p<0.05$

$\mathrm{NW}=$ Patients not willing for Implant treatment

$\mathrm{W}=$ Patients willing for Implant treatment 
Table 3: Test statistics for gender and patient attitude.

\begin{tabular}{|c|c|c|c|c|}
\hline & Female & Male & Total & Fisher's Exact test \\
\hline NW & 6 & 13 & 19 & \multirow{2}{*}{ P value 0.348750} \\
\hline W & 10 & 11 & 21 & \\
\hline Total & 16 & 24 & 40 & \\
\hline
\end{tabular}

Significant $p<0.05$

$\mathrm{NW}=$ Patients not willing for Implant treatment

$\mathrm{W}=$ Patients willing for Implant treatment

Table 4: Test statistics for extent of edentulousness and patient attitude.

\begin{tabular}{|c|c|c|c|c|c|}
\hline & $\begin{array}{c}\text { Partially Edentulous } \\
\text { in Upper arch }\end{array}$ & $\begin{array}{c}\text { Edentulous in } \\
\text { Lower arch }\end{array}$ & $\begin{array}{c}\text { Partially Edentulous } \\
\text { in both arches }\end{array}$ & Total & $\begin{array}{c}\text { Fisher's } \\
\text { Exact test }\end{array}$ \\
\hline NW & 6 & 7 & 6 & 19 & \multirow{2}{*}{ P value } \\
\cline { 1 - 4 } W & 6 & 11 & 4 & 21 & 0.561921 \\
\hline Total & 12 & 18 & 10 & 40 & \\
\hline
\end{tabular}

Significant $p<0.05$

$\mathrm{NW}=$ Patients not willing for Implant treatment

$\mathrm{W}=$ Patients willing for Implant treatment

\section{Discussion}

Restoration with removable partial denture prostheses (RPD) is considered a less than ideal treatment option. The prevalence of caries is 6 times more in RPD patients than in patients with fixed prostheses (FPD). Poor oral hygiene, Loss of abutment teeth, Occlusal and functional deterioration is more with an RPD ${ }^{[2,3]}$. Also, the general need for treatment and prosthodontic follow up is higher than in patients with FPD. On the other hand, dental implant treatment have come a long way since inception and is presently considered the standard of care in restoration of missing teeth ${ }^{[12,19]}$.

In the present study, possibility of dental implant treatment in Kennedy class I and Class II partial denture wearers was assessed, along with the patients' willingness to accept the treatment. The study revealed that almost half (48\%) of the participants were not inclined towards implant treatment for various reasons. Cost of treatment seemed to be the most deciding factor in majority. In a study conducted by Tepper G et al. $2003^{[20]}$. to assess implant acceptance, patient perceived cost and patient satisfaction in Austrian population, it was observed that interest in implants increases with increase in family income. Satisfaction in patients who underwent implant treatment was found to be definitely higher than satisfaction perceived by them when they were only told about implants. Mc Kenna et al. $2016{ }^{[18]}$ concluded that previous implant treatment experience and increased income levels were found to strongly influence willingness to pay for implant treatment. Dental Implant treatment was found to be expensive and unaffordable by patients in Malaysia as reported by a survey by Kohli S et al $2015^{[17]}$.

In the present study a statistically significant difference $(p=0.045)$ was seen in the oral hygiene status of participants willing for implant treatment when compared to those not willing. The mean OHI- $\mathrm{S}$ index value for the willing participants was 1.757 when compared to 2.305 in the unwilling participants. In view of the fact that all the participants in the study are partial denture wearers, importance of oral hygiene can only be reinforced at every opportunity. Periodic recall and check-up is mandatory in RPD wearers [6]. Low OHI- $\mathrm{S}$ index scores in willing participants shows that an increased level of awareness in oral hygiene maintenance has led to a better understanding and positive perspective about improved treatment options. It can also imply that removable partial denture wearers are unaware of the disadvantages of removable prostheses and the benefits of fixed restorative treatment in oral hygiene maintenance, leading to scepticism in removable partial denture wearers about implant treatment. Zimmer et al. ${ }^{[21]}$, Berge et al. ${ }^{[14]}$ Best et al. ${ }^{[22]}$ and Agawaka et al. ${ }^{[23]}$ found in their survey that in only 17 to $20 \%$ of the times dentist is the source of awareness about dental implants. Majority of the information gathered by the patient is through media. It shows an increasing need for the dentists and professional bodies to spread awareness among general population through right information and direct contact which was found to have a positive impact on patient satisfaction ${ }^{[24]}$.

Age, gender and extent of edentulousness show no statistical significance in their distribution between willing and unwilling patients. However when Muller et al $1994{ }^{[25]}$ studied the age related satisfaction in complete dentures and attitude of patients to seek better treatment options, it was found that older patients were more satisfied with their dentures than their younger counterparts who were comparatively less sceptical about implants. This discrepancy in finding could be attributed to the low sample size in the present study.

\section{Conclusion}

A cross sectional study of partially edentulous denture wearers reveals that only around 50\% percent of the population is inclined towards implants as treatment opt for replacement of missing teeth. Within the limitations of the study it can be concluded that patient perceived higher cost of implants and less awareness about importance of oral hygiene maintenance and periodontal health can be associated with unwillingness of removable partial denture wearers to opt for implant treatment.

\section{References}

1. Devlin H Replacement of missing molar teeth--a prosthodontic dilemma. Br Dent J. 1994; 8;176(1):31-3.

2. Linda Dula J, Kujtim Sh. Shala, Teuta PustinaKrasniqi, Teuta Bicaj, Enis Ahmedi F. The influence of removable partial dentures on the periodontal health of abutment and non-abutment teeth Eur J Dent. 2015; 9(3):382-386.

3. Linda Dula J, Enis Ahmedi F, Zana Lila-Krasniqi D, Kujtim Sh Shala. Clinical Evaluation of Removable Partial Dentures on the Periodontal Health of Abutment Teeth: A Retrospective Study Open Dent J. 2015; 9:132139.

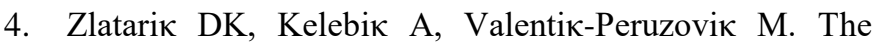


effect of removable partial dentures on periodontal health of abutment and non-abutment teeth. J Periodontal. 2002; 73:137

5. Mojon P, Rentsch A, Butz-Jorgensen E. Relationship between prosthodontic status, caries and periodontal disease in geriatric population. Int J Prosthodent. 1995; 8:564-71.

6. Bassi F, Mantecchini G, Carossa S, Preti G. Oral conditions and aptitude to receive implants in patients with removable partial dentures: a cross-sectional study. Part I. Oral conditions Journal of Oral Rehabilitation 1996; 23:50-54.

7. Bergman B, Hugoson A, Olsson CO. Caries, periodontal and prosthetic findings in patients with removable partial dentures a ten-year longitudinal study. J Prosthet Dent. 1982; 48:506-14.

8. Yeung AL, Lo EC, Chow TW, Clark RK. Oral health status pf patients 5 to 6 years after placement of cobaltchromium removable partial dentures. J Oral Rehabil. 2000; 27:183-9.

9. Preshaw PM, Walls AW, Jakubovics NS, Moynihan PJ, Jepson NJ, Loewy Z. Association of removable partial denture use with oral and systemic health. J Dent. 2011; 39:711-9.

10. Rodan R, Al-Jabrah O, Ajarmah M. Adverse effects of removable partial dentures on periodontal status and oral health of partially edentulous patients. JRMS. 2012; 19:53-8.

11. Rissin L, Feldman RS, Kapur KK, Chauncey HH. Sixyear report of the periodontal health of fixed and removable partial denture in abutment teeth. J Prosthet Dent. 1985; 54:461-7.

12. Adell R, Lekholm U, Rockler B, Branemark PI. A 15year study of osseointegrated implants in the treatment of the edentulous jaw. Int. J. Oral. Surg. 1981; 10(6):387416.

13. Adell R, Eriksson B, Lekholm U, Branemark PI, Jemt T. Long-term follow-up study of osseointegrated implants in the treatment of totally edentulous jaws. Int. J. Oral Maxillofac. Implants. 1990; 5(4):347-359.

14. Berge TI. Public awareness, information sources and evaluation of oral implant treatment in Norway. Clin. Oral Implants Res. 2000; 11(5):401-408.

15. Gbadebo OS, Lawal FB, Sulaiman AO, Ajayi DM. Dental implant as an option for tooth replacement: The awareness of patients at a tertiary hospital in a developing country Contemp Clin Dent. 2014; 5(3):302-306.

16. Al-Johany S, Al Zoman HA, Al Juhaini M, Al Refeai M. Dental patients' awareness and knowledge in using dental implants as an option in replacing missing teeth: A survey in Riyadh, Saudi ArabiaSaudi Dent J. 2010; 22(4):183-188.

17. Kohli S, Bhatia S, Kaur A, Rathakrishnan T. Patients awareness and attitude towards dental implants Indian J Dent. 2015; 6(4):167-171.

18. McKenna G, Tada S, Woods N, Hayes M, DaMata C, Allen PF Tooth replacement for partially dentate elders: A willingness-to-pay analysis. J Dent. 2016; 53:51-6.

19. Jivraj S, Chee W. Rationale for dental implants. British Dental Journal. 2006, 661-665.

20. Tepper G, Haas R, Mailath G, Teller C, Bernhart T, Monov G. Representative marketing-oriented study on implants in the Austrian population. II. Implant acceptance, patient-perceived cost and patient satisfaction. Clin. Oral Implants Res. 2003; 14(5):634642.

21. Zimmer CM, Zimmer WM, Williams J, Liesener J. Public awareness and acceptance of dental implants. Int. J. Oral Maxillofac. Implants. 1992; 7(2):228-232.

22. Best HA. Awareness and needs of dental implants by patients in New South Wales. Aust. Prosthodont. J. 1993; 7:9-12.

23. Akagawa Y, Rachi Y, Matsumoto T, Tsuru H. Attitudes of removable denture patients toward dental implants. J. Prosthet. Dent. 1988; 60(3):362-364.

24. Tepper G, Haas R, Mailath G, Teller C, Zechner W, Watzak G. Representative marketing-oriented study on implants in the Austrian population. I. Level of information, sources of information and need for patient information. Clin. Oral Implants Res. 2003; 14(5):621633.

25. Muller F, Wahl G, Fuhr K. Age-related satisfaction with complete dentures, desire for improvement and attitudes to implant treatment. Gerodontology. 1994; 11(1):7-12. 